\title{
Author Correction: A B-ARR-mediated cytokinin transcriptional network directs hormone cross- regulation and shoot development
}

\author{
Mingtang Xie ${ }^{1,2}$, Hongyu Chen ${ }^{3}$, Ling Huang ${ }^{4}$, Ryan C. O'Neil ${ }^{1,5}$, Maxim N. Shokhirev ${ }^{4}$ \& Joseph R. Ecker ${ }^{1,2}$
}

Correction to: Nature Communications https://doi.org/10.1038/s41467-018-03921-6, published online 23 April 2018

The original version of this Article contained an error in Fig. 3. Panel b was inadvertently duplicated and the correct panel $\mathrm{c}$ was originally omitted. This error has been corrected in both the PDF and HTML versions of the Article.

Published online: 22 May 2018

\begin{abstract}
(c) (i) Open Access This article is licensed under a Creative Commons Attribution 4.0 International License, which permits use, sharing, adaptation, distribution and reproduction in any medium or format, as long as you give appropriate credit to the original author(s) and the source, provide a link to the Creative Commons license, and indicate if changes were made. The images or other third party material in this article are included in the article's Creative Commons license, unless indicated otherwise in a credit line to the material. If material is not included in the article's Creative Commons license and your intended use is not permitted by statutory regulation or exceeds the permitted use, you will need to obtain permission directly from the copyright holder. To view a copy of this license, visit http://creativecommons.org/licenses/by/4.0/.
\end{abstract}

(C) The Author(s) 2018

\footnotetext{
${ }^{1}$ Plant Biology Laboratory, and Genomic Analysis Laboratory, The Salk Institute for Biological Studies, La Jolla, CA 92037, USA. ${ }^{2}$ Howard Hughes Medical Institute, The Salk Institute for Biological Studies, La Jolla, CA 92037, USA. ${ }^{3}$ Department of Computer Science, Dartmouth College, Hanover, NH 03755, USA. ${ }^{4}$ The Razavi Newman Integrative Genomics and Bioinformatics Core Facility, The Salk Institute for Biological Studies, La Jolla, CA 92037, USA.

${ }^{5}$ Bioinformatics Program, University of California at San Diego, La Jolla, CA 92093, USA. Correspondence and requests for materials should be addressed to J.R.E. (email: ecker@salk.edu)
} 